\title{
Analysis of Influence Factors of Large-scale Wind Power Consumption Benefit during Market Transition Period
}

\author{
Qingshan Zhao ${ }^{1}$, Xiaojun $\mathrm{Li}^{1}$, Zhong Fang ${ }^{1}$, Wenjun Gong ${ }^{1}$, Zhongming Zhang ${ }^{1}$, \\ Qiannan Fan ${ }^{2, ~ a}$ and Zhuhan Long \\ ${ }^{1}$ State Grid Xin Jiang Electric Power Company, Xinjiang 830000, China; \\ ${ }^{2}$ School of Economics and Management, North China Electric Power University, Beijing 102206, \\ China.
}

a781025917@qq.com

Keywords: wind power, consumption benefit, market transition period.

\begin{abstract}
With the new round of power system reform, China has increased the support for new energy. In recent years, the scale of wind power generation is increasing, and the development of wind power is significant rapid. This paper has systematically reviewed the key factors that affect the wind power consumption benefits, established the system dynamics models and simulated the effect of the key factors in different scenarios. At last, we comprehensively evaluate the value of on-grid wind power from direct economic benefits, auxiliary service costs and environmental benefits.
\end{abstract}

\section{Introduction}

At present, China has become the largest energy consumer. To ensure energy security and environmental protection, it's an important measure to develop new energy, adjust the energy structure and realize the sustainable development [1]. With the new round of power system reform, China has increased the support for new energy [2], especially in recent years under the relevant policy guidance, wind power generation is rapidly developing in China [3]. Up to 2014, the annual new installed capacity of wind power is 19.81 million kilowatts, and the cumulative installed capacity reached 96.37 million kilowatts, accounting for $7 \%$ of the total power generation capacity, $27 \%$ of global wind power installed capacity; in addition, the on-grid wind power is 153.4 billion $\mathrm{kWh}$ in 2014 , accounting for $2.78 \%$ of total generation [4].

The new energy powers' technical and economic characteristics are distinct from conventional ones, such as wind power [5]. The fluctuation, intermittent and anti-peaking features significant affect the consumption. The paper is going to analysis the influence factors and choose the important ones for dynamic simulation. It helps to make clear of the main factors that influence the on-grid economic benefits, guide future policy making and promote the development of large-scale wind power. Ultimately, achieve energy reduction targets in power industry.

\section{Analysis of Key Factors Affecting Wind Power Consumption Benefits}

\subsection{Analysis of Direct Economic Benefits.}

Direct economic benefits equals to wind power generation revenue minus generation costs. Thus, the main influence factors include the following three: 1)Wind power generation: research the impact of technological advances and government policy support on total wind power generation; 2)Generation revenue: research the benefits of wind power enterprises under the existing system of electricity price, which is equivalent to feed-in price multiply average generation; 3)Generation cost: the cost for wind power enterprises include construction cost, operating cost and management cost.

\subsection{Analysis of Ancillary Service Costs.}

Wind power has characteristics of intermittent and uncertainty so that the electricity system has to increase the additional reserve capacity to maximize utilize of wind resources and guarantee the safety and reliable operation of the system, which generates a certain ancillary service costs[6]. 
First, since wind power presents the anti-peaking characteristics, the difference between peak and valley will increase when the wind power access to the system. Second, the notable fluctuation of the capacity factor increases the difficulty of system frequency regulation, and then affects the operation of wind turbines. Thus, the fluctuation and instability of wind power will result in a huge increasing in spinning reserve demands of the system.

Based on the above analysis, wind power auxiliary service cost can be divided into three types: load shifting cost, frequency regulation cost and spinning reserve cost: 1)Load shifting cost: mainly refers to the cost of maintaining active power balance and system stability after wind power participation. The value is equivalent to the reduced generation benefits of conventional power which participates in the depth load shifting; 2)Frequency regulation cost: mainly refers to the cost of maintaining a stable system frequency after participation of wind power; 3)Spinning reserve cost: mainly refers to the cost of balancing instability of wind power.

\subsection{Analysis of Environmental Benefits.}

It will generate $\mathrm{CO} 2$, nitrides, sulfides and other pollutants during the conventional power generation processing. While, as a renewable energy, wind power can replace part of conventional energy providing no environmental pollution [7].

Thus, this paper will measure the environmental benefits of wind power by analysis the reduced emission benefits. And discuss output size and emission reduction benefits in the support of related technologies and policies. As we all know, wind power can replace the thermal power generation to some extent, reduce the use of coal resources, and achieving the air pollutants emission reduction benefits

\section{Analysis of wind power consumption benefits based on system dynamics}

Comprehensive value of wind power determines its relative competitiveness and development potential to conventional energy sources. This chapter based on system dynamics theory, researches the most significant and measurable benefits, analyzes the direct economic benefits, ancillary services costs and environmental benefits. And building system dynamics model assesses the value of wind power generation comprehensively.

\subsection{Description of System Dynamics}

System Dynamics (referred to as the SD) was founded to research system dynamic complexity by Professor Jay W. Forrester at MIT in 1956 [8]. It bases on feedback control theory and uses computer simulation technology to study the relationship among complex systems structure, function and dynamics behavior. It emphasized to understand the system composition and the interaction of each part, to conduct a dynamical simulation experiment to study the dynamical changes of system behavior and trends in inputting different system parameters or strategies, the analysis steps are shown below.

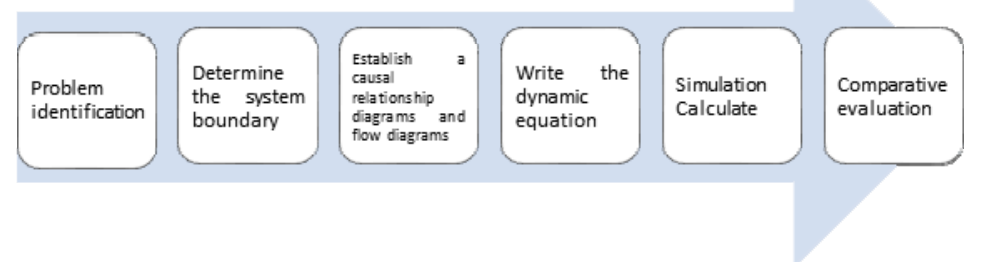

Fig. 1. System dynamics analysis steps

\subsection{Model for Direct Economic Benefits Analysis}

Analysis based on section 2. A, we can use wind power generation, generation revenue and generation cost as the system boundary conditions to build system dynamics model of direct economic benefits to analyze, then continue to boundary refinement. We can get the system flow diagram shown in Fig 2, the meanings of related factors are shown in the table below. 


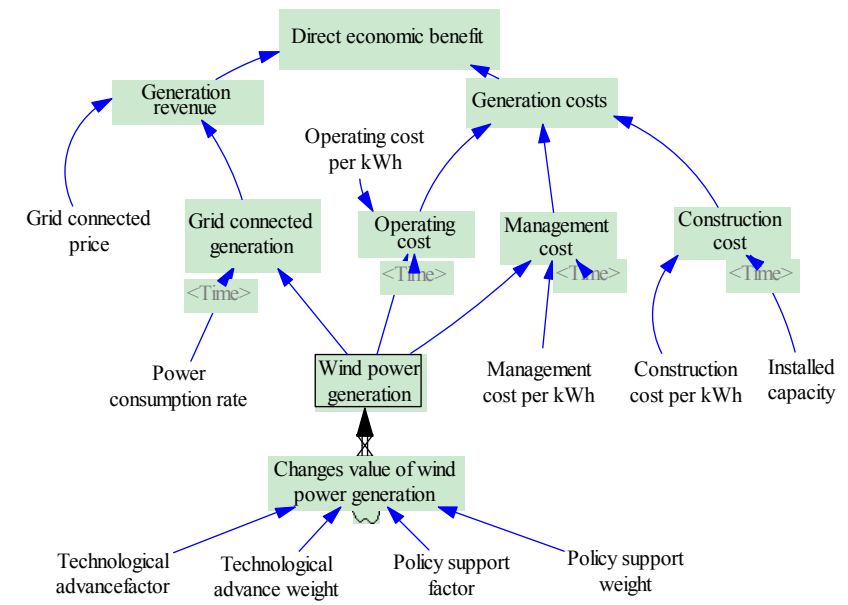

Fig. 2. System flow diagrams of wind power direct economic benefits analysis

Table 1 factors related to direct economic benefits

Factors

Operating cost

Management cost

Construction cost

On-grid generation

On-grid price

Power consumption rate

Changes of wind power generation

Technical progress factor

Technological advances weight

Policy support factor

Policy support weight

\section{Meanings of factors}

Guarantee the daily power production and normal operation Material, labor and other costs for production activities

The cost is used to build power stations and related facilities

The output generation that wind power companies delivered to the grid.

The price that grid enterprises pay for wind power.

The percentage that power consumption accounts for generation in a wind power enterprise.

Changes of wind power generation per unit time, it may be positive or negative. And the amount depends on smart grid technology and government incentives.

Through the technology development of wind power, it brings increasing generation.

Determine the importance of technological progress factor in all factors in the system.

The government issued the related supporting policies, which bring generation increasing.

Determine the importance of policy support factor in all of the factors in the system.

It gives the direct economic benefits of system dynamics equations on the basis of clear meaning and effect of each factor. System equations can accurately reflect the relationship among the factors, and are key parts of the analysis and problem solving. It includes state variable equations, rate equations and auxiliary variable equations.

(1) Equation of State

$Q_{\text {wind }}(t)=Q_{\text {wind }}(0)+\int_{0}^{t} q_{\text {wind }}(\pi) d \pi$

Where, $Q_{\text {wind }}(t)$ is the wind power generation, $\mathrm{kWh} ; Q_{\text {wind }}(0)$ is the initial generation of wind power, $\mathrm{kWh} ; q_{\text {wind }}(t)$ is the changes of wind power generation, $\mathrm{kWh} /$ Year

(2) Rate equation

$$
q_{\text {wind }}(t)=\frac{t(t) * W_{t}(t)+p(t) * W_{p}(t)}{W_{t}(t)+W_{p}(t)} * Q_{\text {wind }}(t-1)
$$

Where, $\mathrm{t}(\mathrm{t})$ is technical progress factor; $w_{(t)}$ is technological advances weight; $\mathrm{p}(\mathrm{t})$ is policy support factor; $W_{p}(t)$ is the policy support weight.

(3) Auxiliary equations

$$
\begin{aligned}
& E(t)=B(t)-C(t) \\
& B(t)=Q(t) * p(t)
\end{aligned}
$$




$$
\begin{aligned}
& C(t)=C_{o}(t)+C_{m}(t)+C_{c}(t) \\
& Q(t)=Q_{\text {wind }}(t) *(1-\xi) \\
& C_{o}(t)=Q_{\text {wind }}(t) * c_{o}(t) \\
& C_{m}(t)=Q_{\text {wind }}(t) * c_{m}(t) \\
& C_{c}(t)=\Theta(t) * c_{c}(t)
\end{aligned}
$$

Where, $\mathrm{E}(\mathrm{t})$ is the direct economic benefits of wind power, Yuan; $\mathrm{B}(\mathrm{t})$ is the generation revenue, Yuan; $\mathrm{C}(\mathrm{t})$ is the generation cost, Yuan; $\mathrm{Q}(\mathrm{t})$ is feed-in energy, $\mathrm{kWh} ; \mathrm{P}(\mathrm{t})$ is feed-in tariff, Yuan / $\mathrm{kWh}$; $C_{o}(t)$ is operating cost, Yuan; ${ }^{C_{m}}(t)$ is management cost, Yuan; ${ }_{c}(t)$ is construction cost, Yuan; $\xi_{\text {is power }}$ consumption rate; ${ }^{C_{o}}(t)$ is operating cost per unit electricity, Yuan / $\mathrm{kWh} ;{ }^{c_{m}}(t)$ is management cost per unit electricity, Yuan / $\mathrm{kWh} ;{ }^{c_{c}(t)}$ is construction cost per unit capacity, Yuan / kVA; ${ }^{\Theta}(t)$ is installed capacity, kVA.

\subsection{Model for Auxiliary Service Costs Analysis}

Analysis based on section II . B, we can use peaking shaving cost, FM cost and spinning reserve cost as the system boundary conditions to build system dynamics model of ancillary service costs to analyze, then continue to boundary refinement. We can get the system flow diagram shown in Fig 3,

\begin{tabular}{|c|c|}
\hline Factors & Meanings of factors \\
\hline Load shifting cost per unit & The cost of load shifting per unit. \\
\hline Frequency regulation cost per unit & The cost of frequency regulation per unit. \\
\hline Reduced generation per unit time & $\begin{array}{c}\text { The reduced generation of conventional power due to the depth } \\
\text { peaking shaving. }\end{array}$ \\
\hline $\begin{array}{l}\text { Reserve cost per unit time } \\
\text { The actual output of the conventional } \\
\text { generator }\end{array}$ & $\begin{array}{l}\text { The increased traditional spinning reserve cost per unit time. } \\
\text { The actual power generation of conventional generator. }\end{array}$ \\
\hline
\end{tabular}
the meanings of related factors are shown in the table below.

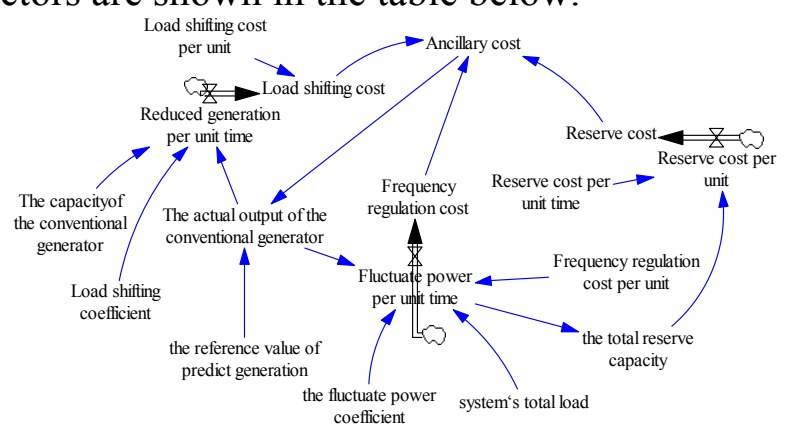

Fig. 3. System flow diagrams of wind power ancillary service costs analysis

Table 2: factors related to ancillary service costs

\subsection{Model for Environmental Benefits}

Analysis based on section II. C, we can use the total amount of wind power generation and benefits of emission reduction as the system boundary conditions to build system dynamics model of environmental benefits, then continue to boundary refinement. We can get the system flow diagram shown in Fig 4, the meanings of related factors are shown in the table below.

Table 3: factors related to environmental benefits

\section{Factors}

The reduced pollution in amount

The reduced pollution per $\mathrm{kWh}$

The unit value of reduced pollution

The benefit of reduction pollution

\section{Meanings of factors}

The emissions reductions that wind power brings.

Pollutants that fossil fuel power generated per kilowatt-hour.

Saving cost through reducing unit pollutant emission.

Wind power replaces fossil energy generation to reduce pollutant emissions and thus get the benefit of reduction. 


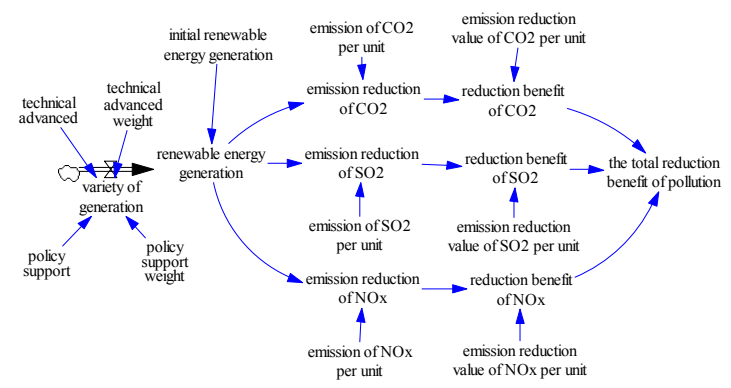

Fig. 4. System flow diagram of wind power environmental benefits analysis.

In summary, given the system dynamics equations. Among them, the state equations and rate equations are the same with section 4.1. Therefore, only auxiliary equations are described in detail.

\section{The example analysis}

Section III built analytical model of wind power consumption benefit, which is based on system dynamics. This section will use Vensim PLE software to solve the model emulation. Because the analyses of direct economic benefits, auxiliary service costs and environmental benefits are substantially same, this paper will select certain wind power datum of a regional power system during planning period, and take the model of direct economic benefits as example to analyze.

\subsection{Set Variable Parameters}

Based on China's actual situation of wind power, the above system dynamics model's parameters can be set. The wind power price is $0.49 \mathrm{Yuan} / \mathrm{kwh}$, power consumption rate is $6 \%$, operating cost is 0.112 Yuan / kwh, construction cost is 5140 Yuan / kw, management cost is 0.054 Yuan / kw, installed capacity is $937,900 \mathrm{kw}$, the initial generation is 25.83 billion $\mathrm{kwh}$, technological advances weight is 0.4 , policy support weight is 0.6 , technological progress factor is 0.1 , policy support factor is 130 [9-11].

\subsection{Solving Process}

Based on above settings, we use Vensim software and then construct three scenarios:

(1) The impact of technological progress and policy incentives on wind power generation.

In the model, technological progress factor is adjusted from 0.1 to 0.2 , policy support factor is adjusted from 0.2 to 0.4 , and other parameters remain unchanged. The simulation results as shown. It can be seen that technological progress and domestic policy incentives can increase wind power generation, further improve the proportion and meet the power supply demand under conditions of low-carbon energy.

(2) The impact of wind power generation on direct economic benefits

Based on the result of last simulation, wind power generation has changed from the initial state of 25.83 billion $\mathrm{kWh}$ to 28.49 billion $\mathrm{kWh}$ through technological progress and policy incentives. In other parameters fixed condition, the simulation results are shown below. It can be seen when the generation is increasing, the direct economic benefits are in a state of fluctuation. When the generation is 27.33 billion $\mathrm{kWh}$, the largest direct economic benefits achieved.

(3) The impact of increasing generation and reducing price of wind power on direct economic benefits

Recently, the National Development and Reform Commission issued perfect onshore wind power, photovoltaic electricity benchmark price policy notice. The document clearly states the benchmark prices of onshore wind power and photovoltaic electricity will be reduced year by year with the development of the scale. Therefore, based on the simulation analysis of the second scenario, the price changes from $0.51 \mathrm{Yuan} / \mathrm{kW}$ to $0.43 \mathrm{Yuan} / \mathrm{kW}$, and the simulation results are shown below. It can be seen that the price kept at 0.51 Yuan / $\mathrm{kW}$ unchanged before 2014, then the direct economic benefits remain unchanged. When the price continues to drop, the overall direct economic benefits reduce and show a downward trend. 

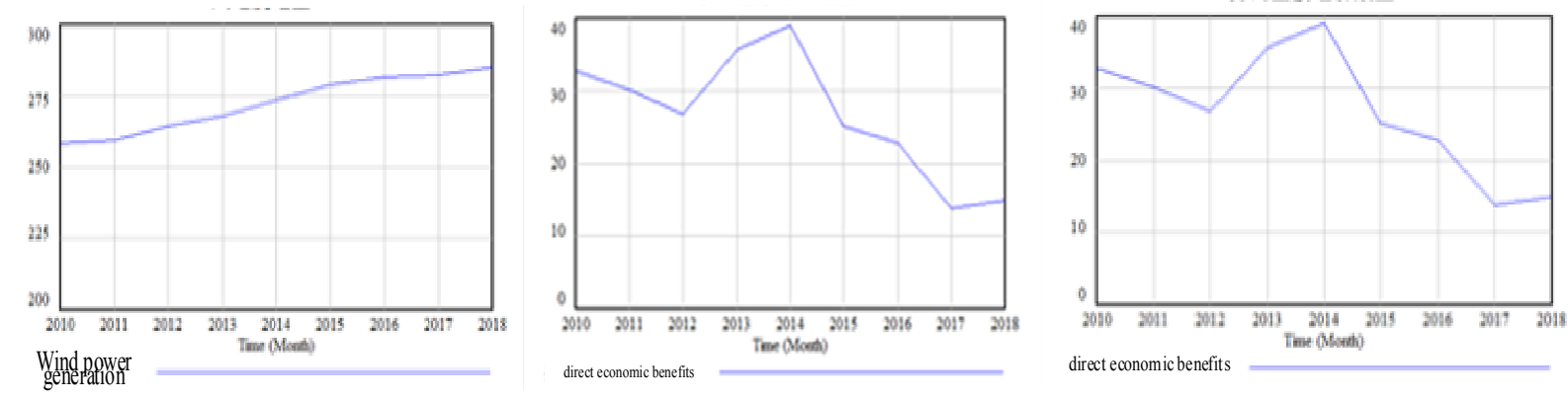

Fig. 5. The result of the solving process

\section{Summary}

This paper reviews and analyzes the key factors that impact wind power consumption, establishes system dynamics models that generation and feed-in tariff impact direct economic benefits, and uses Vensim software to simulate.

The simulation results show the following points: First, technology advances and policy incentives are key factors to wind power, and there is a positive correlation with generation; Second, the increase of wind power generation will change the trend of direct economic benefits significantly; Third, under the situation that price is reducing and generation continues to improve, the direct economic benefits will show a decreasing trend.

\section{References}

[1]. Li Chen, Zhou Lisha, Zeng Ming. New energy grid system dynamics modeling and simulation of the impact of the power market [J]. East China Electric Power, 2012, 40(10): 1675-1679.

[2]. Li JF. China wind power outlook 2012. Beijing: China: Environment Science Press; 2012.

[3]. Zeng Ming, Electric power system reform and new energy power system [N]. China Electric Power, 2015-07-07001.

[4]. Hou Dexin. Chinese electric power industry of new energy power generation model research [J]. Chinese \& Foreign Entrepreneurs, 2015, 26: 19-20.

[5]. Li Junfeng, China wind power outlook 2012[M]. Beijing: China Environmental Science Press, 2012: 1-10.

[6]. Wang Z, Qin H, Lewis JI. China's wind power industry: policy support, technological achievements, and emerging challenges. Energy Policy 2012, 51(8): 1-8.

[7]. Zhao X, Wang F, Wang M. Large-scale utilization of wind power in China: obstacles of conflict between market and planning. Energy Policy 2012, 48(2): 22-32.

[8]. HAN Dong, YAN Zheng, SONG Yi-qun, et al. Dynamic assessment method for smart grid based on system dynamics [J]. Automation of Electric Power Systems, 2012, 36(3): 16- 21.

[9]. Zhao Z-Y, Yan H, Zuo J, Tian Y-X, Zillante G. A critical review of factors affecting the wind power generation industry in China. Renewable Sustainable Energy Rev 2013, 19: 499-508.

[10]. Ling Y, Cai X. Exploitation and utilization of the wind power and its perspective in China. Renewable Sustainable Energy Rev 2012, 16(4):2111-7.

[11]. Hu Z, Wang JH, Byrne J, Kurdgelashvili L. Review of wind power tariff policies in China. Energy Policy 2013, 53: 41-50. 